\title{
Textural Properties of Food Used in Studies of Mastication
}

\section{J.-S. WANG and C.S. STOHLER ${ }^{1}$}

The University of Michigan, School of Dentistry, Stomatognathic Physiology Laboratory, Ann Arbor, Michigan 48109-1078

Foods are known to influence jaw elevator muscle activity in chewing. With the long-range goal of gaining insight into force control and modeling muscle recruitment, these initial experiments were performed to determine the textural properties of commonly used test food.

Experiments were carried out by means of a standard Instron instrument, equipped with a compression cell. A stylus with 45-degree cuspal angulation and an opposing copper-plated lower arch was used for approximation of the natural situation. The breakage force characteristics of a single peanut, a carrot cube, beefstick, and monkey chow were determined.

The peanut demonstrated the steepest and beefstick the least steep force build-up, with breaking forces of $104 \mathrm{~N}$ (Newtons) for monkey chow, $66 \mathrm{~N}$ for the carrot, and $52 \mathrm{~N}$ for the peanut. No clear breakage point was found with beefstick; the force build-up showed an initial plateau at $25 \mathrm{~N}$, which was followed by a significantly steeper force increase to peak.

We conclude that each of the test foods commonly used in studies of mastication had particular breakage characteristics in terms of its force-time curve.

J Dent Res 69(9):1546-1550, September, 1990

\section{Introduction.}

Black (1895) stated that "the only way to arrive at any satisfactory conclusion as to the force ordinarily employed, was to contrive means of weighing the stress necessary to crush the ordinary food." It has been reported that the myoelectric activity pattern of the jaw muscles differs among various types of foods (Ahlgren, 1966; Moller, 1966; Hiiemae, 1978; Haraldson and Ingerval, 1979; Hylander and Johnson, 1989). Harder food usually produces greater myoelectric amplitudes of the jaw-closing musculature. In addition, chewing rate, chewing cycle duration, and the amount of lateral mandibular excursion are influenced by the nature of the test food (Luschei and Goodwin, 1974; Bates et al., 1975; Hiiemae, 1978). With the long-range goal of elucidation of mechanisms of force control and modeling of muscle recruitment, it is necessary that the textural properties of commonly used test foods be determined.

The purposes of this research were (1) to measure the breaking force of different foods of standardized size and shape, and (2) to record the force-time relationship during the initial bolus compression.

\section{Materials and methods.}

Experiments were performed by means of an Instron ${ }^{\circledR}$ Universal Testing Instrument (Instron Corp., Canton, MA 02021) equipped with a compression cell (Tension/Compression Cell, up to $4900 \mathrm{~N}$, Instron Engineering Corp., Quincy, MA). A

Received for publication November 1, 1989

Accepted for publication April 3, 1990

${ }^{1}$ To whom correspondence and reprint requests should be addressed

This study was supported by NIH-NIDR grant DE8606. stainless-steel stylus with 45-degree cuspal angulation was used for simulation of the upper molar cusp. A model of the mandibular arch, consisting of an autopolymerized resin core with copper-plated surface, was secured firmly to the load table. The lower dentition included 14 intact, human teeth. A switching relay was connected between the stylus and the lower arch, so that whenever tooth contact was established, the Instron driving circuit was shut down (Fig. 1). For experiments with monkey chow, a model of the lower arch of an adult female Macaca fascicularis was used, in addition to the human dentition employed in the other tests.

The following test foods were included: (1) high-protein monkey chow (\#5045, Purina Mills ${ }^{\circledR}$ Inc., St. Louis, MO) of cylindrical shape and $13 \mathrm{~mm}$ in diameter; (2) fresh carrot cubes of $2,3,5$, and $10 \mathrm{~mm}$ thicknesses; (3) a half peanut (dryroasted blanched peanut, Food $\mathrm{Club}^{\circledR}$, Skokie, IL) with an approximate thickness of $5 \mathrm{~mm}$; (4) beefstick (Bridgford ${ }^{\circledR}$, Bridgford Foods Corp., Chicago, IL) without skin, and with an approximate thickness of $8 \mathrm{~mm}$.

After the test food was placed on the occlusal table of the first lower molar, the stylus tip was positioned on the center of the test food. For recording of the subtle force changes in the compression cycle, cross-head speeds of $2 \mathrm{~cm} / \mathrm{min}$ and 5 $\mathrm{cm} / \mathrm{min}$ were selected. Although these speeds are slower than those found in mastication, only small differences have been found between series of measurements with different rates of

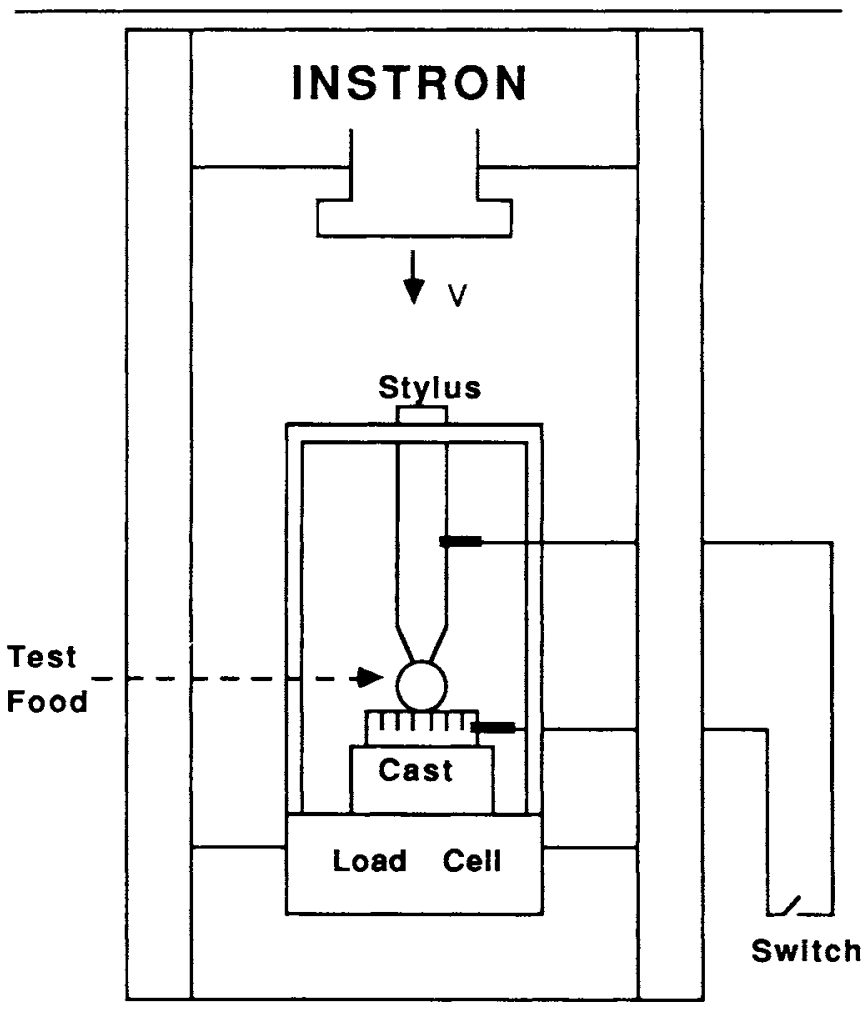

Fig. 1-Experimental instrumentation. 
loading in terms of the force-deformation curves (Olthoff, 1986). Stress, sensed by the load cell during food compression, was plotted on a polygraphic system with a paper speed of either $5 \mathrm{~cm} / \mathrm{min}$ or $50 \mathrm{~cm} / \mathrm{min}$. The peanut, carrot, and monkey chow were tested with both cross-head speeds. For beefstick, however, only the larger cross-head speed was used. Twenty specimens were measured in each food and cross-head speed category. Experiments with monkey chow were performed with casts of both the human and monkey dentition. For the carrot, an additional five trials were performed with each of the $2^{-}, 3^{-}$, $5^{-}$, and $10-\mathrm{mm}$ cubes.

Maximum breakage forces (MBF) of various test foods, compressed by different cross-head speeds, were analyzed by means of two-way analysis of variance for evaluation of the influence of cross-head speeds, test foods, and the interaction between them. The significance of the use of either the human or monkey dentition was statistically evaluated by means of the unpaired $t$ test. The influence of food thickness was assessed by one-way analysis of variance.

The breakage patterns (force-time relationship) were further investigated by identification of parameters such as breakage point (BP), initial breakage force (IBF), initial force build-up (IFB), maximum breakage force (MBF), total compression time (TCT), and temporal location of MBF in the compression cycle (TL). These parameters are illustrated in Fig. 2. BP was defined by any increase in compression force that was followed by an immediate decrease of more than 4 $\mathrm{N}$ (Newtons). This facilitated distinction between stress relaxation and food deformation. The force magnitude of the first BP was regarded as IBF. IBF, divided by the time needed to arrive at IBF, was defined as IFB. TL was defined by the fraction of time needed to reach MBF within a total compression cycle. IBF in this study is equal to the definition of fracturability; MBF is equal to hardness (Brennan et al., 1970; Bourne and Comstock, 1981).

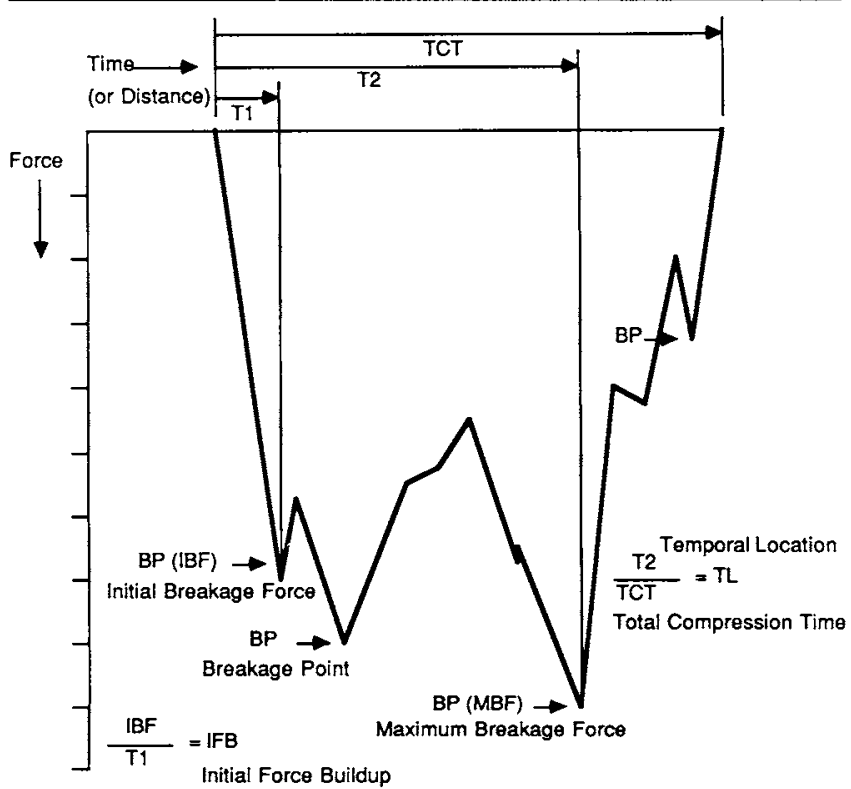

Fig. 2-Diagramatic representation of the definitions. Horizontal arrows indicate the positions of breakage points (BP), which were defined by any increase and then a decrease of more than $4 \mathrm{~N}$. Force magnitude of the first BP was initial breakage force (IBF) which, when divided by the time needed (T1), was regarded as initial force build-up (IFB). Maximum force found in all BPs was maximum breakage force (MBF). The time needed to reach $\mathrm{MBF}$ was $\mathrm{T} 2$, which, divided by total compression time (TCT), was the temporal location of MBF (TL).

\section{Results.}

Force-time relationship. - Force-time curves of the different test foods, with a cross-head speed of $5 \mathrm{~cm} / \mathrm{min}$, are presented in Fig. 3. The mean and standard deviations of various force categories and breakage patterns are summarized in Tables 1 and 2.

(A) Beefstick - The force-time curve of beefstick showed the lowest initial force build-up (IFB) $(3.1 \mathrm{~N} / \mathrm{s}$, with a crosshead speed of $5 \mathrm{~cm} / \mathrm{min}$ ), which can be explained by the tenderness of beefstick. Beefstick tended to flow rather than break, exhibiting a defined breakage point (BP) of less than 1 per compression cycle, on average. At $60 \%$ of total compression time (TCT), the force reached its maximum of about $25.4 \mathrm{~N}$, then decreased slightly to form a force plateau that was maintained until late in the compression cycle. Because of the specific property of beefstick, food residuals were usually trapped between tooth antagonists, producing an end force of more than $400 \mathrm{~N}$ at the final compression stage.

(B) Peanut. - The peanut showed the highest IFB $(53.8 \mathrm{~N} /$ $\mathrm{s}$, with a cross-head speed of $5 \mathrm{~cm} / \mathrm{min}$ ), representing the rigidity of the food. At about $20 \%$ of TCT, the force had already reached $50 \mathrm{~N}$ on average. Because maximum breakage force (MBF) was the first BP in six of nine tests of the peanut, the initial breakage force (IBF) of the peanut $(49.4 \mathrm{~N})$ was close to $\mathrm{MBF}$. Following the point of breakage, the compression curve was quite irregular. Due to the brittleness of the peanut, the average number of BPs was found to be 3.2 per cycle. Finally, and similarly to beefstick, an end force of more than $400 \mathrm{~N}$ was always observed.

(C) Monkey chow. - Due to the rigidity of monkey chow, the initial slope of the force-time curve showed a rapid increase. IFB (46 N/s at a cross-head speed of $5 \mathrm{~cm} / \mathrm{min}$ ) was only a little less than that of the peanut. Monkey chow was further characterized by its brittleness, which was reflected by the highest number of BPs (4.8/cycle) among all the test foods. Interestingly, in six of nine trials, MBF was the last $\mathrm{BP}$ in

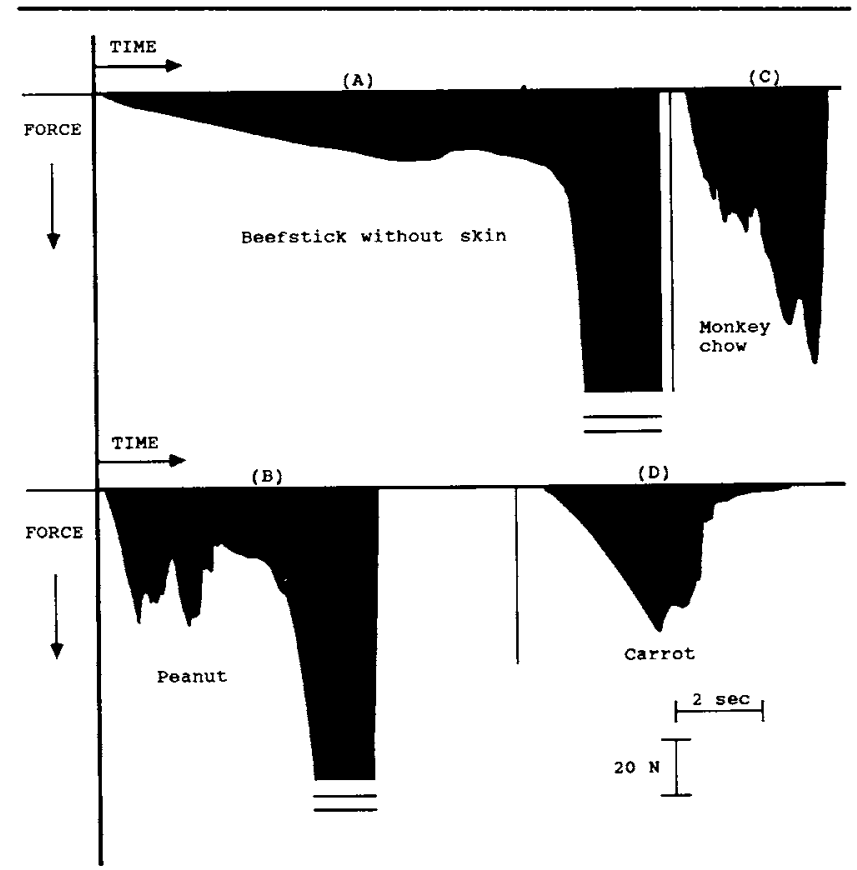

Fig. 3-Force-time curves of various test foods (cross-head speed, 5 $\mathrm{cm} / \mathrm{min}$; paper speed, $50 \mathrm{~cm} / \mathrm{min}$ ). (A) Beefstick without skin, (B) peanut, (C) monkey chow, (D) carrot. End forces of beefstick and the peanut are not displayed fully (see text). 
TABLE 1

INITIAL FORCE BUILD-UP, INITIAL BREAKAGE FORCE, AND MAXIMUM BREAKAGE FORCE (MEAN \pm S.D.) FOR VARIOUS TEST FOODS (CROSS-HEAD SPEED, $5 \mathrm{~cm} / \mathrm{min}$ )

\begin{tabular}{|c|c|c|c|}
\hline Test Food & $\begin{array}{c}\text { Initial Force } \\
\text { Build-up (IFB) }\end{array}$ & $\begin{array}{c}\text { Initial } \\
\text { Breakage } \\
\text { Force (IBF) } \\
\end{array}$ & $\begin{array}{c}\text { Maximum } \\
\text { Breakage } \\
\text { Force (MBF) }\end{array}$ \\
\hline $\begin{array}{l}\text { Beefstick } \\
(n=9)\end{array}$ & $3.1 \pm 0.2$ & $25.4 \pm 3.8$ & $25.4 \pm 3.8^{*}$ \\
\hline $\begin{array}{l}\text { Peanut } \\
(n=9)\end{array}$ & $53.8 \pm 17.2$ & $49.4 \pm 11.6$ & $51.7 \pm 10.1^{*}$ \\
\hline $\begin{array}{l}\text { Mon. chow } \\
(\mathrm{n}=10)\end{array}$ & $46.0 \pm 9.7$ & $34.3 \pm 20.1$ & $103.9=24.4$ \\
\hline $\begin{array}{l}\text { Carrot } \\
(n=9)\end{array}$ & $17.5 \pm 3.4$ & $66.3 \pm 9.2$ & $66.3 \pm 9.2$ \\
\hline
\end{tabular}

${ }^{*}$ Because of a specific property of beefstick and the peanut, food residuals were usually trapped between tooth antagonists, causing an end force of more than $400 \mathrm{~N}$ at the final compression stage. However, end force was not included in the consideration of MBF, because it is unlikely to occur in natural mastication.

TABLE 2

BREAKAGE PATTERNS OF DIFFERENT TEST FOODS (CROSSHEAD SPEED, $5 \mathrm{~cm} / \mathrm{min}$ )

\begin{tabular}{lccc}
\hline \hline Test Food & $\begin{array}{c}\text { No. of } \\
\text { Breakage Point* } \\
\text { (BP) (unit/cycle) }\end{array}$ & $\begin{array}{c}\text { Total Compression } \\
\text { Time (TCT) }(\mathrm{s})\end{array}$ & $\begin{array}{c}\text { Temporal Location } \\
\text { of MBF (TL) } \\
(\% \text { from the } \\
\text { start point) }\end{array}$ \\
\hline $\begin{array}{l}\text { Beefstick } \\
(\mathrm{n}=9)\end{array}$ & $0.7 \pm 0.5$ & $13.6 \pm 0.2$ & $59.3 \pm 11.0$ \\
$\begin{array}{l}\text { Peanut } \\
(\mathrm{n}=9)\end{array}$ & $3.2 \pm 0.4$ & $7.0 \pm 0.5$ & $20.4 \pm 10.7$ \\
$\begin{array}{l}\text { Mon. chow } \\
(\mathrm{n}=10)\end{array}$ & $4.8 \pm 2.6$ & $4.6 \pm 1.6$ & $72.1 \pm 16.0$ \\
$\begin{array}{l}\text { Carrot } \\
(\mathrm{n}=9)\end{array}$ & $1.3 \pm 0.5$ & $5.9 \pm 2.0$ & $54.5 \pm 10.5$ \\
\hline
\end{tabular}

${ }^{*}$ Any increase and then a decrease of more than $4 \mathrm{~N}$ was counted as a breakage point; end force was not included in the counting. In beefstick, almost no clear breakage was found, only flow. In the peanut, MBF was the first BP in six of nine trials; on the contrary, in six of nine trials, $\mathrm{MBF}$ was the last $\mathrm{BP}$ in monkey chow. All of the MBF were the first $\mathrm{BP}$ in the carrot.

monkey chow, which was temporally located at $72 \%$ of the full compression cycle. This feature was quite different from the peanut's. Monkey chow also showed the highest hardness $(\mathrm{MBF}=103.9 \mathrm{~N})$. Following the point of fracture, force

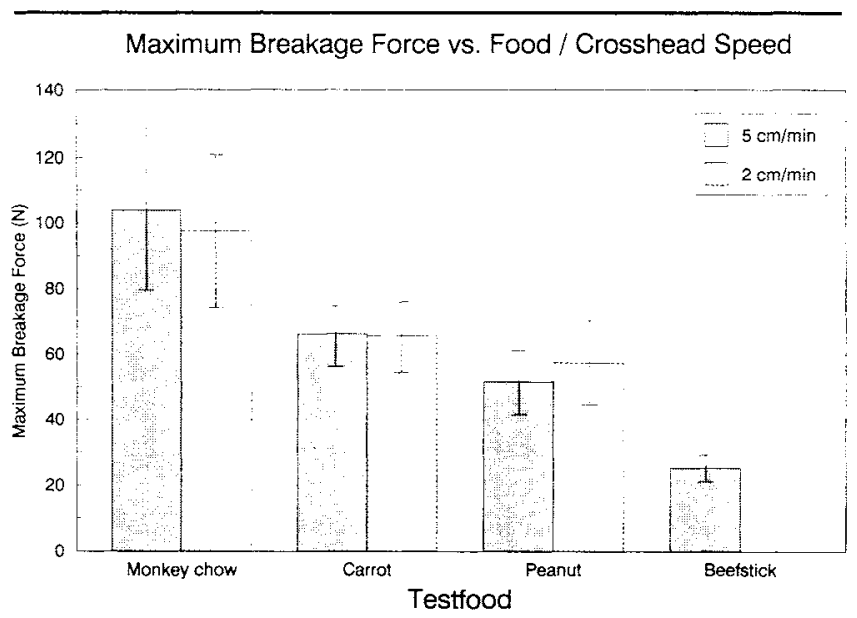

Fig. 4-Maximum breakage force vs. test food / cross-head speed.
TABLE 3

ANOVA TABLE FOR A TWO-FACTOR ANALYSIS OF VARIANCE ON MAXIMUM BREAKAGE FORCE

\begin{tabular}{lrrrrr}
\hline \hline Source & df & $\begin{array}{l}\text { Sum of } \\
\text { Squares }\end{array}$ & $\begin{array}{c}\text { Mean } \\
\text { Square }\end{array}$ & F-test & p value \\
\hline Food (A) & 2 & 426.499 & 213.249 & 81.861 & $0.0001^{*}$ \\
$\begin{array}{l}\text { Cross-head } \\
\text { speed (B) }\end{array}$ & 1 & 0.901 & 0.901 & 0.346 & 0.5576 \\
AB & 2 & 4.515 & 2.257 & 0.867 & 0.4232 \\
Error & 114 & 296.972 & 2.605 & & \\
\hline
\end{tabular}

*Statistical significance.

TABLE 4

THE EFFECT OF THE OCCLUSAL TABLE ON MAXIMUM BREAKAGE FORCE (MBF) DURING COMPRESSION OF MONKEY CHOW WITH A CROSS-HEAD SPEED OF $5 \mathrm{~cm} / \mathrm{min}$

\begin{tabular}{lcr}
\hline & Test & \\
Dentition & Number & MBF $(\mathrm{N})^{*}$ \\
\hline Human & 20 & $101.04 \pm 20.87$ \\
Macaca fascicularis & 12 & $91.34 \pm 15.58$ \\
\hline
\end{tabular}

*The results are expressed as mean \pm S.D.

$t$ test: $\mathrm{p}=0.32$; no statistical significance.

decayed rapidly because the fractured pieces fell off the occlusal table, and the stylus established contact with its counterpart. Although monkey chow was clearly thicker than the peanut, TCT of monkey chow was less than that of the peanut.

(D) Carrot. - The initial slope increased moderately; IFB was about $17.5 \mathrm{~N} / \mathrm{s}$ when a cross-head speed of $5 \mathrm{~cm} / \mathrm{min}$ was used. The first breakage point was MBF, which was located at $55 \%$ of the full duration of the compression cycle. MBF was $66 \mathrm{~N}$, on average. The number of BPs was 1.3 per cycle, indicating that following fracturing, the force declined in steps and was rarely associated with a rapid increase of force. This represents the low cohesiveness of the xylem tissue. The broken pieces also fell off the occlusal table. The average duration of TCT was only $5.9 \mathrm{~s}$, which was shorter than the corresponding values for the peanut and beefstick.

Statistical analysis. - By means of multivariate analysis of variance (Wilks' Lambda F statistics), the force-time curves of different test foods were shown to be significantly different from each other $(p<0.001, s)$. Parameters of the force-time curve were also found to be significantly different between test foods by one-way analysis of variance $(p<0.001, s)$.

Based upon 20 trials with the $5 \mathrm{~cm} / \mathrm{min}$ cross-head speed, MBF was $103.9 \pm 24.4$ for monkey chow, $66.3 \pm 9.2 \mathrm{~N}$ for the carrot, and $51.7 \pm 10.1 \mathrm{~N}$ for the peanut. Skinned beefstick did not exhibit a breaking point, as observed with the other test foods; in fact, an initial force plateau was recorded which was related to the force needed for the beefstick to be punctured. The average force of this initial plateau was 25.4 $\pm 3.8 \mathrm{~N}$. Results are summarized in Fig. 4. At final compression stage, the carrot and the monkey chow fell off the occlusal table; however, beefstick and the peanut showed an end force because food residuals were trapped between tooth antagonists.

Two-way analysis of variance showed that there was no interaction between cross-head speed and test food in the measurement of MBF ( $p=0.42$, n.s.). Different cross-head speeds had no statistically significant influence on the results $(\mathrm{p}=$ 0.56 , n.s.). However, the type of food was significant in the determination of MBF $(p=0.0001, s$.). Statistical results are summarized in Table 3. Multiple comparison (Fisher test and Scheffé's F test) showed that the MBFs of different types of 
TABLE 5

THE EFFECT OF BOLUS (CARROT) SIZE ON MAXIMUM BREAKAGE FORCE (MBF) WITH A CROSS-HEAD SPEED OF $5 \mathrm{~cm} / \mathrm{min}$

\begin{tabular}{lcc}
\multicolumn{3}{c}{$5 \mathrm{~cm} / \mathrm{min}$} \\
Thickness & $\begin{array}{c}\text { Test } \\
\text { Number }\end{array}$ & MBF $(\mathrm{N})^{*}$ \\
\hline $10 \mathrm{~mm}$ & 5 & $65.9 \pm 9.6$ \\
$5 \mathrm{~mm}$ & 5 & $63.3 \pm 4.4$ \\
$3 \mathrm{~mm}$ & 5 & $58.6 \pm 12.3$ \\
$2 \mathrm{~mm}$ & 5 & $50.8 \pm 4.9$ \\
\hline
\end{tabular}

*The results are expressed as mean \pm S.D.

One-way analysis of variance: $p=0.1$; no statistical significance.

food were significantly different from each other. Although the human and monkey occlusal morphology are quite different, the effect of the type of occlusion was of no significance with monkey chow ( $p=0.32$, n.s.) (Table 4$)$. No statistically significant influence was found when carrots of variable thickness were used ( $p=0.1$, n.s.). However, there was a tendency for thicker food to require a slightly higher MBF; these data are summarized in Table 5 .

\section{Discussion.}

Food properties have been studied extensively in the field of food science. The test food is usually prepared in bite-sized pieces that are studied by means of compression instruments. Based on the force-time curves obtained, the mechanical properties are described by parameters such as hardness, cohesiveness, adhesiveness, viscosity, elasticity, brittleness (fracturability), "chewiness", and "gumminess" (Szczesniak, 1963, 1975). Commonly used instruments for assessment of these properties include the General Foods Texturometer (Friedman et al., 1963; Brennan et al., 1970) and the Instron Universal Testing Machine (Bourne et al., 1966; Shama and Sherman, 1973). In this experiment, the Instron Instrument was used for simulation of the food compression process. A stainless-steel stylus with a 45-degree angulation tip was constructed to model the upper molar cusp, a lower dental cast was attached to the load cell, and a relay was interfaced in the power line to the device that sensed the existence of contact between stylus and teeth. Experiments focused on the initial compression, which is representative of the first chewing cycle in a masticatory sequence. Due to the intrinsically changing nature of the bolus, however, subsequent cycles in vivo may show quite different textural properties of the bolus.

We found that each test food possessed specific properties, as seen by significantly different force-time curves. It was also noticed that the force-time curve of soft food was more reproducible than that of hard or brittle food. This is in agreement with Brennan et al. (1970), who reported that reproducibility decreases with increasing hardness of the material under test.

At the final compression stage, the peanut and beefstick showed a higher end force than had been reported in the literature. This was because the stylus was driven to establish occlusal contact rather than being stopped in the vicinity of maximum intercuspation. Instruments used in food science leave a distance of $1 \mathrm{~mm}$ or so open between stylus and occlusion. This higher end force was associated with residuals of food being squeezed between antagonists in the final stage of bolus crushing. Such great end forces are unlikely to occur in natural mastication, since tooth contact is most likely not established in the first chewing stroke, particularly with foods such as the peanut and beefstick. This has been confirmed by Hylander and Crompton (1986), who reported the absence of tooth contact during the initial compression of monkey chow in Macaca fascicularis. In human subjects, Atkinson and Shepherd (1967) observed that during the first two or three chewing cycles; the teeth approached one another but did not make contact; however, in succeeding chewing strokes, as the bolus was softened, tooth contact was found highly likely to occur.

In terms of hardness, referred to as maximum breakage force (MBF) in our study, results are in agreement with the standard hardness rating scale used in food science (Szczesniak et al., 1963). Fresh carrot was found to be harder than the cocktail peanut, and the peanut harder than beefstick. Food properties are known to influence masticatory behavior (Bates et al., 1975; Hiiemae, 1978). Harder food is associated with greater muscle activity. In fact, it has been reported that the chewing of a peanut is associated with greater masseteric mean peak electromyographic activity than with gum, an apple, or bread (Ahlgren, 1966; Haraldson and Ingerval, 1979). Higher mean peak chewing forces have also been reported for the peanut than for cheese or gum (Gibbs et al., 1981; DeBoever et al., 1978). On the other hand, Howell and Brudevold (1950) reported that raisins resulted in a greater peak chewing force than the peanut. Clearly, hardness is not the only mechanical food property shaping masticatory behavior. Foods are complex mechanical systems, frequently inhomogeneous. In addition, different food preparations may lead to diverse results.

The morphology of the occlusal table was not of significance for maximum breakage force (MBF), and inherent food properties were more important than cross-head speed in terms of $\mathrm{MBF}$. Although food thickness was not found to affect MBF significantly, there was a tendency for thicker food to induce higher MBF.

From this study, we conclude that each test food has particular textural properties reflected in characteristic details of its force-time curves. It is generally assumed that each foodstuff shapes the masticatory behavior in terms of force generation and jaw movement. So that insight into masticatory force and mandibular movement control may be gained, knowledge of the food in terms of its textural properties is essential.

\section{Acknowledgment.}

We thank Dr. William Hylander for his helpful comments and suggestions.

\section{REFERENCES}

AHLGREN, J. (1966): Mechanism of Mastication, Acta Odontol Scand (Suppl 44) 24:1-109.

ATKINSON, H.F. and SHEPHERD, R.W. (1967): Masticatory Movements and the Resulting Force, Arch Oral Biol 12:195-202.

BATES, J.F.; STAFFORD, G.D.; and HARRISON, A. (1975): Masticatory Function - a Review of the Literature (II). Speed of Movement of the Mandible, Rate of Chewing and Forces Developed, $J$ Oral Rehabil 2:349-369.

BLACK, G.V. (1895): An Investigation of the Physical Characters of the Human Teeth in Relation to their Diseases, and to Practical Dental Operations, together with Physical Characters of the Filling Materials, Dental Cosmos 37:469-484.

BOURNE, M.C. and COMSTOCK, S.H. (1981): Effect of Degree of Compression on Texture Profile Parameters, $J$ Texture Studies $12: 201-216$.

BOURNE, M.C.; MOYER, J.C.; and HAND, D.B. (1966): Measurement of Food Texture by a Universal Testing Machine, Food Technol 20:522-526.

BRENNAN, J.G.; JOWITT, R.; and MUGHSI, O.A. (1970): Some Experiences with the General Foods Texturometer, $J$ Texture Studies $1: 167-184$.

DE BOEVER, J.A.; McCALL, W.D.; HOLDEN, S.; and ASH, M.M. 
(1978): Functional Occlusal Forces: an Investigation by Telemetry, $J$ Prosthet Dent 40:326-333.

FRIEDMAN, H.H.; WHITNEY, J.E.; and SZCZESNIAK, A.S. (1963): The Texturometer - a New Instrument for Objective Texture Measurement, $J$ Food Sci 28:390-396.

GIBBS, C.H.; MAHAN, P.E.; LUNDEEN, H.C.; BREHNAN, K.; WALSH, E.K.; SINKEWIZ, S.L.; and GINSBERG, S.B. (1981): Occlusal Forces during Chewing - Influences of Biting Strength and Food Consistency, J Prosthet Dent 46:561-567.

HARALDSON, T. and INGERVAL, B. (1979): Muscle Function during Chewing and Swallowing in Patients with Osteointegrated Oral Implant Bridges. An Electromyographic Study, Acta Odontol Scand 37:207-216.

HIIEMAE, K.M. (1978): Mammalian Mastication: a Review of the Activity of the Jaw Muscles and the Movements they Produce in Chewing. In: Development, Function, and Evolution of Teeth, P.M. Butler and K.A. Joysey, Eds., London: Academic Press, pp. 359-398.

HOWELL, A.H. and BRUDEVOLD, F. (1950): Vertical Forces Used during Chewing of Food, $J$ Dent Res 29:133-136.

HYLANDER, W.L. and CROMPTON, A.W. (1986): Jaw Movement and Patterns of Mandibular Bone Strain during Mastication in the Monkey Macaca fascicularis, Arch Oral Biol 31:841-848.

HYLANDER, W.L. and JOHNSON, K.R. (1989): The Relationship between Masseter Force and Masseter Electromyogram during Mastication in the Monkey Macaca fascicularis, Arch Oral Biol 34:713-722.

LUSCHEI, E.S. and GOODWIN, G.M. (1974): Patterns of Mandibular Movement and Jaw Muscle Activity during Mastication in Monkey, $J$ Neurophysiol 37:954-966.

MOLLER, E. (1966): The Chewing Apparatus, Acta Physiol Scand (Suppl 280) 69:1-228.

OLTHOFF, L.W. (1986): Comparison of Force-Deformation Characteristics of Artificial Food and Several Natural Foods for Chewing Experiments. In: Comminution and Neuromuscular Mechanisms in Human Mastication, PhD Thesis, University of Utrecht, pp. 65-83.

SHAMA, F. and SHERMAN, P. (1973): Evaluation of Some Textural Properties of Foods with the Instron Universal Testing Machine, $J$ Texture Studies 4:344-353.

SZCZESNIAK, A.S. (1963): Classification of Textural Charactcristics, J Food Sci 28:385-389.

SZCZESNIAK, A.S. (1975): General Foods Texture Profile Revisited - Ten Years Perspective, $J$ Texture Studies 6:5-17.

SZCZESNIAK, A.S.; BRANDT, M.A.; and FRIEDMAN, H. (1963): Development of Standard Rating Scales for Mechanical Parameters of Texture and Correlation between the Objective and the Sensory Methods of Texture Evaluation, J Food Sci 28:397-403. 